\title{
PENGUKURAN KEPUASAN PENGGUNA DAN PENINGKATAN LAYANAN SISTEM INFORMASI PELAYANAN DESA DAN DATA TERPADU (SILADDU) KABUPATEN MAJALENGKA
}

\author{
Budiman $^{1}$, Sandi Fajar Rodiyansyah ${ }^{2}$, Dede Abdurahman ${ }^{3}$ \\ Program Studi Informatika, Fakultas Teknik, Universitas Majalengka ${ }^{123)}$ \\ Email : budikms28@gmail.com ${ }^{1}$,galuh29@gmail.com², dzildan@gmail.com³
}

\begin{abstract}
SILADDU or the Integrated Data Services Information System is an application to record data of the population of a village. This application is expected to help village officials in administering the settlement. In addition, the application is expected to become the reference in government programs such as direct assistance from the government in providing information about who will be given help, because this application helps classify the population data based on the level of economic ability, educational level, marital status, age, gender and others. This application is relatively new so attracted me as a researcher to examine the level of user satisfaction. Thus the researchers conducted this study in order to become one of the source application developers have to pay attention to the satisfaction of his application.
\end{abstract}

\section{Keywords: SILADDU, User Satisfaction, Aplication}

\section{PENDAHULUAN}

Sistem Informasi dibangun dari pengguna yang tidak mengerti teknologi sampai pengguna yang mengerti teknologi. Pengguna yang tidak mengerti teknologi pada umumnya adalah masyarakat luas seperti petani, pedagang, sopir, tukang becak dan sebagainya, sedangkan masyarakat yang mengerti teknologi pada umumnya masyarakat yang mempunyai dasar atau profesi yang berkaitan dengan teknologi, misalnya pustakawan, fendor, programer, admin, dan lain sebagainya. Sehingga sistem informasi dapat dipahami dan di manfaatkan dengan efektif dan efisien Berdasarkan informasi yang tertera pada Website BAPPEDA Kabupaten Majalengka hasil sementara pencacahan Sensus Penduduk 2010, penduduk Kabupaten Majalengka berjumlah 1.166.473 jiwa yang terdiri atas 582.892 laki-laki dan 583.581 perempuan. Sex ratio masih menunjukkan proporsi laki-laki yang hampir seimbang dengan penduduk perempuan yaitu sebesar 99,88 persen. Ratarata tingkat kepadatan penduduk Kabupaten Majalengka mencapai 969 jiwa/km2. Persebaran penduduk di Kabupaten Majalengka di setiap kecamatan belum merata. Kecamatan yang paling padat penduduknya adalah Kecamatan Jatiwangi yaitu $2.062 \mathrm{jiwa} / \mathrm{km} 2$, sedangkan kecamatan yang paling jarang penduduknya adalah Kecamatan Kertajati yaitu 306 jiwa/km2. Jumlah yang sedemikian banyank tentu tidak bisa seopenuhnya dicatat hanya dengan menggunakan proses administrasi biasa dengan menggunakan kertas atau bahkan hanya dengan Microsoft Excel saja. Tentunya dibutuhkan sistem yang yang dapat menampung jutaan data administrasi penduduk tersebut. Maka dari itu pemerintah Kabupaten Majalengka menyediakan sebuah sistem berbentuk software atau perangkat lunak yang bernama SILADDU yang dapat membantu aparatur pemerintahan desa untuk "membukukan" data kependudukan tersebut.

SILADDU atau Sistem Informasi Pelayanan Data Terpadu merupakan sebuah aplikasi untuk mencatat data kependudukan suatu desa. Aplikasi ini diharapkan dapat membantu aparatur desa dalam mengelola administrasi kependudukan. Selain itu aplikasi ini diharapkan menjadi rujukan dalam program-program pemerintah seperti bantuan langsung dari pemerintah dalam memberikan informasi tentang siapa yang akan diberi bantuan, karena aplikasi ini membantu mengelompokan data penduduk berdasarkan tingkat kemampuan ekonomi, tingkat pendidikan, status perkawinan, usia, jenis 
kelamin dan lain sebagainya. Walaupun terbilang baru, aplikasi ini diharapkan dapat memberi dampak pada kinerja pemerintah desa dalam mengurus administrasi kependudukan.

Dari aplikasi yang terbilang baru ini penulis ingin menganalisa sejauh mana aplikasi ini berfungsi dengan mengukur tingkat kepuasan pengguna aplikasi. Dalam penelitian ini penulis menggunakan model End User Computing Satisfaction (EUCS) dari Doll dan Torkzadeh (1998) yang terdiri dari lima dimensi yang digunakan untuk mengukur kepuasan pengguna sistem yaitu Content, Accuracy, Format, Ease Of Use, dan Timeliness.

\section{Tinjauan Pustaka}

\section{A. Kepuasan}

Kata kepuasan (satisfaction) berasal dari bahasa latin "satis" (artinya cukup baik, memadai) dan "facio" (melakukan atau membuat). Kepuasan bisa diartikan sebagai upaya pemenuhan kebutuhan atau membuat sesuatu memadai. Oxford Advance Learner's dictionary mendeskripsikan kepuasan sebagai "the good feeling that you have when you achieved something or when something that you wanted to happen does happen." Cadotte, Woodruff \& Jenkins [1] "Kepuasan dikonseptualisasikan sebagai perasaan yang timbul setelah mengevaluasi pengalaman." Oliver [1] "Kepuasan adalah fenomena rangkuman atribut bersama-sama dengan emosi konsumsi lainnya." Adianto, D., \& Sujadi, H. (2016). Aplikasi Sistem Pendukung Keputusan Pemilihan Jurusan SiswaSiswi SMA (Mipa/Ips/Bahasa) Menggunakan Metode Ahp.

\section{B. User Satisfaction}

Definisi User Satisfaction menurut berbagai ahli sangat beragam, adapun definisi kepuasan pengguna yang dikemukakan [2], "satisfaction is person's feelings of pleasure or disappointment resulting from comparing a product's perceived performance (or outcome) in relation to his or her expectations". Yang artinya bahwa kepuasan adalah perasaan orang akan kesenangan atau kekecewaan yang disebabkan membandingkan hasil kinerja sebuah produk dengan harapannya.

Sedangkan menurut Westbrook menyatakan bahwa "Penilaian evaluatif global terhadap pemakaian/konsumsi produk". [1] menyatakan "The Consumer Fulfillment response", yaitu "penilaian bahwa fitur produk atau jasa, atau produk/jasa itu sendiri, memberikan tingkat pemenuhan berkaitan dengan konsumsi yang menyenangkan, termasuk tingkat underfulfillment dan over-fulfillment".

Kepuasan pengguna merupakan reaksi emosional jangka pendek pengguna terhadap kinerja jasa tertentu. Pengguna menilai tingkat kepuasan atau ketidakpuasan mereka setelah menggunakan jasa dan menggunakan informasi ini untuk memperbaharui persepsi mereka tentang kualitas jasa, tetapi sikap terhadap kualitas tidak bergantung pada pengalaman pakai pada informasi dari mulut ke mulut atau dari iklan [1]. Namun, pengguna harus benar-benar menggunakan suatu jasa untuk mengetahui apakah mereka puas atau tidak dengan hasilnya. Oleh karena kepuasan adalah keadaan emosional, reaksi pascapembelian mereka dapat berupa kemarahan, ketidakpuasan, kejengkelan, netralitas, kegembiraan, atau kesenangan.

Untuk mengetahui efektivitas sistem informasi maka yang dapat digunakan sebagai ukuran adalah kepuasan pengguna. Kepuasan pengguna merupakan salah satu indikator keberhasilan pengembangan sistem informasi [3]. Kepuasan pengguna akhir merupakan akumulasi dari perasaan dan cara pandang yang berbeda terhadap pengiriman informasi dalam bentuk produk maupun layanan [4]. Hal ini menggambarkan secara keseluruhan tentang kepuasan pengguna mengenai sistem informasi. Kepuasan pengguna sistem informasi dapat diukur dengan menggunakan enam variabel, yaitu kelengkapan fungsi/fitur, stabilitas/keandalan, kemudahan penggunaan, inovasi, keamanan, dan fleksibilitas [5]. Kualitas Sistem mempunyai pengaruh signifikan terhadap Kepuasan Pengguna [6]. Kepuasan pengguna dapat memotivasi pengguna untuk lebih mengoptimalkan pemanfaatan sistem informasi untuk menunjang efisiensi dan efektivitas dalam proses belajar, khususnya mahasiswa universitas Majalengka.

Kepuasan pengguna akhir sistem informasi dapat digunakan sebagai tolak ukur keberhasilan suatu sistem informasi. Kepuasan pengguna akhir ini kemudian menjadi bagian dalam pengembangan model keberhasilan sistem informasi. Sistem informasi yang sesuai kebutuhan dan harapan pengguna adalah sistem informasi yang berkualitas, cepat dalam menampilkan informasi, aktual, dapat digunakan sebagai pertimbangan dalam pengambilan keputusan dan tepat dengan kebutuhan yang diinginkan. Untuk memenuhi kebutuhan akan sistem informasi yang baik diperlukan sistem perancangan yang baik, serta sistem pemrograman yang baik dan mampu memanjakan pengguna dengan memberikan dan mengembangkan berbagai fasilitas untuk mengakses informasi yang disediakan. 
Tingkat kepuasan pengguna juga menjadi salah satu tolok ukur dari keberhasilan penerapan suatu aplikasi atau sistem. Agar dapat tercipta stabilitas belajar yang baik dan nyaman dari para mahasiswa, maka harus didukung oleh ketahanan sistem informasi yang handal, tentunya dengan sistem yang diimplementasikan secara optimal, sehingga dapat memberikan rasa puas dan kepercayaan pengguna aplikasi atau sistem yang disediakan untuk memenuhi kebutuhan masyarakat desa.

Kepuasan pengguna dapat tercapai apabila produk yang digunakan oleh pengguna sesuai dengan harapan [2]. Bila harapan seorang pengguna terhadap suatu produk tercapai, maka untuk pengembangan produk selanjutnya akan lebih mudah untuk mempertahankan dan mendapatkan pengguna yang setia terhadap produk tersebut. Terdapat tiga tingkatan dalam pengukuran kepuasan pelanggan:

1. Harapan lebih tinggi dari kinerjanya (berarti pelanggan sangat terpuaskan dengan produk yang dikonsumsinya)

2. Harapan sama dengan kinerjanya (berarti pelanggan terpuaskan dengan produk yang dikonsumsi)

3. Harapan lebih rendah dari kinerjanya (berarti pelanggan tidak terpuaskan dengan produk yang dikonsumsinya).

Terdapat beberapa metode untuk mengukur kepuasan pengguna yaitu antara lain:

1. Mendengarkan keluhan dan menampung saran dari pengguna sistem

Metode ini dilakukan dengan menyediakan pusat pelayanan pengguna yang memudahkan pengguna untuk menyampaikan saran dan keluhan terhadap sistem yang digunakan, misalnya dengan menyediakan helpdesk, email khusus.

2. Survei kepuasan pengguna

Metode ini dilakukan dengan cara survey dan pooling secara periodik, dalam hal ini perusahaan menyebarkan kuesioner secara acak atau menelepon pengguna untuk menanyakan tingkat kepuasan pengguna tersebut terhadap sistem yang digunakan.

Survei kepuasan pengguna ini dapat dibagi menjadi:

1. Kepuasan yang disampaikan atau dilaporkan langsung

Responden ditanya secara langsung mengenai beberapa hal untuk mengetahui apakah mereka merasa puas atau tidak terhadap sistem yang mereka gunakan. Studi dengan menggunakan survey ini digunakan untuk mengumpulkan pendapat, kesan, perasaaan dan kebutuhan pengguna untuk dijadikan patokan bagi perusahaan dalam upaya mencapainya.

2. Memperoleh ketidakpuasan

Kuesioner yang disebarkan menampung perbedaan antara tingkat kinerja bisnis yang dirasakan konsumen atau pengguna dengan tingkatharapan pengguna dalam beberapa kategori-kategori tertentu.

3. Analisis masalah

Responden ditanya mengenai masalah yang berhubungan dengan produk dan pelayanan yang diberikan perusahaan pada mereka dan masukan berupa saran atau usulan perbaikan yang mendorong perusahaan untuk meningkatkan kinerjanya.

4. Analisis kepentingan dan kinerja

Responden atau pengguna ditanyai mengenai tingkat pelayanan sistem berdasarkan kepentingannya dibadingkan dengan kinerja perusahaan dalam setiap kategorinya. Berikut ini merupakan matriks atau kuadran analisis kepentingan dan kinerja.

\section{METODE PENELITIAN}

Pada tahapan ini menunjukan gambar tahapan penelitian yang dilakukan oleh penulis/peneliti.

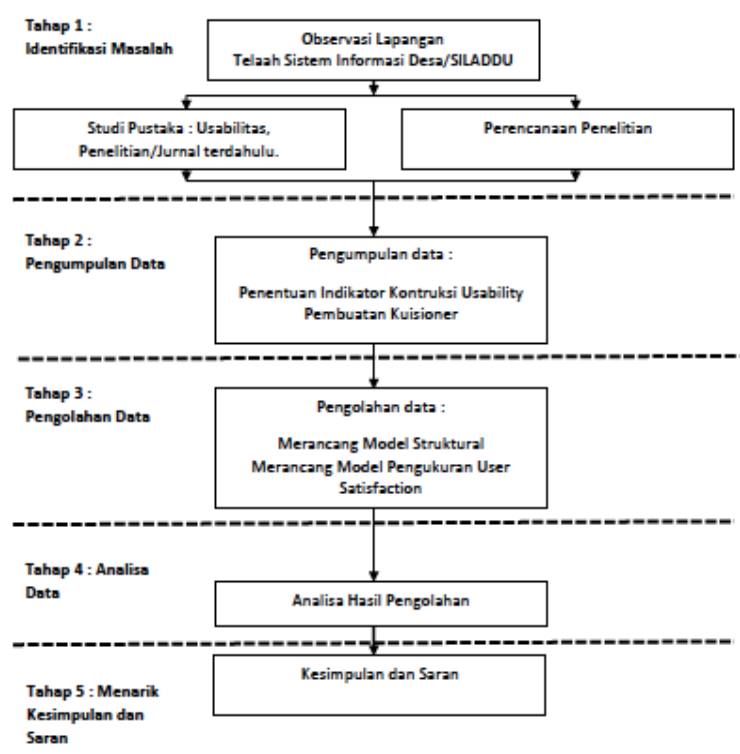

Pada tahap awal penulis atau peneliti menentukan 
judul yang akan ditampilkan untuk penelitian. Selanjutnya peneliti atau penulis melakukan studi pustaka yang mana penulis atau peneliti mencari referensi dan segala ilmu pengetahuan terkait tentang judul yang penulis atau peneliti pilih. Pada tahap berikutnya penulis atau peneliti melakukan observasi menganai keberadaan aplikasi SILaDDU tersebut dengan berkunjung ke beberapa desa yang tidak ditentukan. Setelah melakukan observasi dan dirasa cukup informasi. Selanjutnya penulis atau peneliti menentukan model yang akan dibuat untuk mengukur analisis yang tertera pada judul penelitian dan juga membuat pernyataan yang akan diajukan kepada responden. Setelah itu dilanjutkan dengan membagikan dan setelah diisi oleh responden langsung mengumpulkannnya lagi. Setelah itu penulis atau peneliti mengkalkulasikan data hasil kuisioner yang terkumpul. Setelah itu penulis atau peneliti membuat analisis berdasarkan data yang didapat dan membuat laporan.

\section{HASIL DAN PEMBAHASAN}

\section{A. Gambaran Umum Responden}

Responden dalam penelitian ini adalah pengguna SILADDU. Pengiriman kuesioner dimulai pada minggu ke empat di bulan Mei 2017, dan diambil kembali pada

saat setelah pengisian kuisioner dilakukan. Total kuesioner yang dikirim sebanyak 24 kuesioner. Kuesioner yang kembali sebanyak $20(83,3 \%)$ termasuk 4 kuesioner yang diisi tidak lengkap, sehingga kuesioner yang dapat diolah sebanyak $20(83,3 \%)$.

Adapun rincian jumlah pengiriman dan pengembalian kuesioner dalam penelitian ini ditunjukkan pada tabel berikut ini.

\section{TABEL 1 TINGKAT PENGEMBALIAN KUESIONER}

\begin{tabular}{|c|c|}
\hline Keterangan & Jumlah \\
\hline $\begin{array}{c}\text { Kuesioner yang } \\
\text { dikirimkan }\end{array}$ & 24 \\
\hline Kuesioner yang kembali & 20 \\
\hline $\begin{array}{c}\text { Kuesioner yang diisi tidak } \\
\text { lengkap }\end{array}$ & 20 \\
\hline $\begin{array}{c}\text { Kuesioner yang dipakai } \\
\text { dalam pengolahan data }\end{array}$ & 83,3 \\
\hline $\begin{array}{c}\text { Tingkat pengembalian } \\
\text { (respon rate) }\end{array}$ & 83,3 \\
\hline $\begin{array}{c}\text { Tingkat pengembalian } \\
\text { (respon rate) yang } \\
\text { digunakan }\end{array}$ & \\
\hline
\end{tabular}

\section{A. Deskripsi Variabel Penelitian}

Dalam penelitian ini ada 1 variabel yang digunakan, yaitu variabel kepuasan pengguna aplikasi SILADDU.kepuasan pengguna aplikasi SILADDU yang digunakan ada 11 item pertanyaan. Analisis pada penelitian ini menggunakan deskriptif persentase frekuensi dengan bantuan program SPSS

16.00 untuk mendeskripsikan persepsi responden atas item-item pertanyaan yang diajukan. Adapun kecenderungan jawaban responden terhadap jawaban masing-masing variabel adalah sebagai berikut :

\section{1) Kelengkapan Isi (Conten) SILADDU}

Untuk mengetahui bagaimana tanggapan responden tentang Kelengkapan Isi (Conten) SILADDU, penulis menggunakan analisis deskriptif, dengan cara menyebarkan kuisioner sebanyak 20 lembar sesuai jumlah responden, Adapun penjelasannya sebagai berikut:

TABEL 2 TABEL TANGGAPAN RESPONDEN PERNYATAAN 1

\begin{tabular}{|c|c|c|c|c|}
\hline Skala Pengkuran & Nilai & $\begin{array}{c}\text { Frekuen } \\
\text { si }\end{array}$ & $\begin{array}{c}\text { Nilai } \\
\text { Total }\end{array}$ & $\%$ \\
\hline Sangat Setuju & 5 & 0 & 0 & 0 \\
\hline Setuju & 4 & 16 & 64 & 80 \\
\hline Netral & 3 & 4 & 12 & 20 \\
\hline Tidak Setuju & 2 & 0 & 0 & 0 \\
\hline $\begin{array}{c}\text { Sangat Tidak } \\
\text { Setuju }\end{array}$ & 1 & 0 & 0 & 0 \\
\hline Jumlah & & 20 & 76 & 100 \\
\hline
\end{tabular}

TABEL 3 TABEL CONTENT 1 FREKUENSI OLEH SPSS NO. 1

\begin{tabular}{|rc|r|r|r|c|}
\hline & & Frequency & Percent & $\begin{array}{r}\text { Valid } \\
\text { Percent }\end{array}$ & $\begin{array}{c}\text { Cumulat } \\
\text { ive } \\
\text { Percent }\end{array}$ \\
\hline Valid & $\mathrm{N}$ & 4 & 20.0 & 20.0 & 20.0 \\
& $\mathrm{~S}$ & 16 & 80.0 & 80.0 & 100.0 \\
& Total & 20 & 100.0 & 100.0 & \\
\hline
\end{tabular}

Berdasarkan tabel 2 diatas, bahwa responden yang memberikan tanggapan Sangat Setuju sebanyak $0 \%$. Sedangkan Setuju dengan nilai total sebesar 16 atau $80 \%$, Netral dengan nilai total sebesar 4 
atau $20 \%$, Tidak Setuju dengan nilai total 0 dan begitupun dengan responden yang menyatakan Sangat Tidak Setuju. Dengan demikian dapat disimpulkan bahwa sebagian besar responden menyatakan Setuju terhadap pernyataan nomor 1.

TABEL 4 TABEL TANGGAPAN RESPONDEN PERNYATAAN 2

\begin{tabular}{|c|c|c|c|c|}
\hline Skala Pengkuran & Nilai & $\begin{array}{c}\text { Frekuen } \\
\text { si }\end{array}$ & $\begin{array}{c}\text { Nilai } \\
\text { Total }\end{array}$ & $\%$ \\
\hline Sangat Setuju & 5 & 0 & 0 & 0 \\
\hline Setuju & 4 & 18 & 72 & 20 \\
\hline Netral & 3 & 2 & 6 & 10 \\
\hline Tidak Setuju & 2 & 0 & 0 & 0 \\
\hline $\begin{array}{c}\text { Sangat Tidak } \\
\text { Setuju }\end{array}$ & 1 & 0 & 0 & 0 \\
\hline Jumlah & & 20 & 78 & 100 \\
\hline
\end{tabular}

TABEL 5 TABEL CONTENT 2 FREKUENSI OLEH SPSS NO. 2

\begin{tabular}{|lc|r|r|r|r|}
\hline & $\begin{array}{r}\text { Frequ } \\
\text { ency }\end{array}$ & Percent & $\begin{array}{r}\text { Valid } \\
\text { Percent }\end{array}$ & $\begin{array}{r}\text { Cumulat ive } \\
\text { Percent }\end{array}$ \\
\hline Valid & $\mathrm{N}$ & 2 & 10.0 & 10.0 & 10.0 \\
& $\mathrm{~S}$ & 18 & 90.0 & 90.0 & 100.0 \\
& Total & 20 & 100.0 & 100.0 & \\
\hline
\end{tabular}

Berdasarkan tabel 4 diatas, bahwa responden yang memberikan tanggapan Sangat Setuju sebanyak 0\%. Sedangkan Setuju dengan nilai total sebesar 18 atau $90 \%$, Netral dengan nilai total sebesar 4 atau 20\%, Tidak Setuju dengan nilai total 0 dan begitupun dengan responden yang menyatakan Sangat Tidak Setuju. Dengan demikian dapat disimpulkan bahwa sebagian besar responden menyatakan Setuju terhadap pernyataan nomor 2 .

\section{TABEL 6 TABEL TANGGAPAN RESPONDEN PERNYATAAN}

\begin{tabular}{|c|c|c|c|c|}
\hline Skala Pengkuran & Nilai & Frekuensi & $\begin{array}{c}\text { Nilai } \\
\text { Total }\end{array}$ & $\%$ \\
\hline Sangat Setuju & 5 & 0 & 0 & 0 \\
\hline Setuju & 4 & 14 & 56 & 70 \\
\hline Netral & 3 & 6 & 18 & 30 \\
\hline Tidak Setuju & 2 & 0 & 0 & 0 \\
\hline $\begin{array}{c}\text { Sangat Tidak } \\
\text { Setuju }\end{array}$ & 1 & 0 & 0 & 0 \\
\hline Jumlah & & 20 & 74 & 100 \\
\hline
\end{tabular}

TABEL 7 TABEL CONTENT 3 FREKUENSI OLEH SPSS NO. 3

\begin{tabular}{|c|c|c|c|c|c|}
\hline & & Frequenc & Percent & $\begin{array}{l}\text { Valid } \\
\text { Percent }\end{array}$ & $\begin{array}{l}\text { mulat iv e } \\
\text { Percent }\end{array}$ \\
\hline \multirow[t]{3}{*}{ Valid } & $\mathrm{N}$ & 6 & 30.0 & 30.0 & 30.0 \\
\hline & $\mathrm{S}$ & 14 & 70.0 & 70.0 & 100.0 \\
\hline & Total & 20 & 100.0 & 100.0 & \\
\hline
\end{tabular}

Berdasarkan tabel 6 diatas, bahwa responden yang memberikan tanggapan Sangat Setuju sebanyak 0\%. Sedangkan Setuju dengan nilai total sebesar 14 atau $70 \%$, Netral dengan nilai total sebesar 6 atau 30\%, Tidak Setuju dengan nilai total 0 dan begitupun dengan responden yang menyatakan Sangat Tidak Setuju. Dengan demikian dapat disimpulkan bahwa sebagian besar responden menyatakan Setuju terhadap pernyataan nomor 3 .

2) Keakuratan (Accuracy) SILADDU

Untuk mengetahui bagaimana tanggapan responden tentang Keakuratan (Accuracy) SILADDU, penulis menggunakan analisis deskriptif, dengan cara menyebarkan kuisioner sebanyak 20 lembar sesuai jumlah responden, Adapun penjelasannya sebagai berikut:

TABEL 8 TABEL TANGGAPAN RESPONDEN PERNYATAAN 4

\begin{tabular}{|c|c|c|c|c|}
\hline Skala Pengkuran & Nilai & Frekuensi & $\begin{array}{c}\text { Nilai } \\
\text { Total }\end{array}$ & $\%$ \\
\hline Sangat Setuju & 5 & 0 & 0 & 0 \\
\hline Setuju & 4 & 18 & 72 & 90 \\
\hline Netral & 3 & 2 & 6 & 10 \\
\hline Tidak Setuju & 2 & 0 & 0 & 0 \\
\hline Sangat Tidak Setuju & 1 & 0 & 0 & 0 \\
\hline Jumlah & & 20 & 78 & 100 \\
\hline
\end{tabular}

TABEL 9 TABEL ACCURACY 1 FREKUENSI OLEH SPSS NO. 4

\begin{tabular}{|r|r|r|r|r|}
\hline & Frequency & Percent & $\begin{array}{r}\text { Valid } \\
\text { Perce } \\
\mathrm{nt}\end{array}$ & $\begin{array}{r}\text { Cumulat ive } \\
\text { Percent }\end{array}$ \\
\hline Valid $\mathrm{N}$ & 2 & 10.0 & 10.0 & 10.0 \\
$\mathrm{~S}$ & 18 & 90.0 & 90.0 & 100.0 \\
Total & 20 & 100.0 & 100.0 & \\
\hline
\end{tabular}


Berdasarkan tabel 8 diatas, bahwa responden yang memberikan tanggapan Sangat Setuju sebanyak 0\%. Sedangkan Setuju dengan nilai total sebesar 18 atau $90 \%$, Netral dengan nilai total sebesar 2 atau $10 \%$, Tidak Setuju dengan nilai total 0 dan begitupun dengan responden yang menyatakan Sangat Tidak Setuju. Dengan demikian dapat disimpulkan bahwa sebagian besar responden menyatakan Setuju terhadap pernyataan nomor 4 .

TABEL 10 TABEL TANGGAPAN RESPONDEN PERNYATAAN 5

\begin{tabular}{|c|c|c|c|c|}
\hline $\begin{array}{c}\text { Skala } \\
\text { Pengkuran }\end{array}$ & Nilai & Frekuensi & Nilai Total & $\%$ \\
\hline Sangat Setuju & 5 & 6 & 30 & 30 \\
\hline Setuju & 4 & 13 & 62 & 65 \\
\hline Netral & 3 & 1 & 3 & 5 \\
\hline Tidak Setuju & 2 & 0 & 0 & 0 \\
\hline Sangat Tidak Setuju & 1 & 0 & 0 & 0 \\
\hline Jumlah & & 20 & 95 & 100 \\
\hline
\end{tabular}

TABEL 11 TABEL ACCURACY 2 FREKUENSI OLEH SPSS NO. 5

\begin{tabular}{|c|c|c|c|c|c|}
\hline & & Frequency & Percent & $\begin{array}{r}\text { Valid } \\
\text { Percent }\end{array}$ & $\begin{array}{c}\text { Cumula } \\
\text { tive } \\
\text { Perc } \\
\text { ent }\end{array}$ \\
\hline \multirow[t]{4}{*}{ Valid } & $\mathrm{N}$ & 1 & 5.0 & 5.0 & 5.0 \\
\hline & $S$ & 13 & 65.0 & 65.0 & 70.0 \\
\hline & SS & 6 & 30.0 & 30.0 & 100.0 \\
\hline & Total & 20 & 100.0 & 100.0 & \\
\hline
\end{tabular}

Berdasarkan tabel 11 diatas, bahwa responden yang memberikan tanggapan Sangat Setuju sebanyak 30\%. Sedangkan Setuju dengan nilai total sebesar 13 atau $65 \%$, Netral dengan nilai total sebesar 1 atau 5\%, Tidak Setuju dengan nilai total 0 dan begitupun dengan responden yang menyatakan Sangat Tidak Setuju. Dengan demikian dapat disimpulkan bahwa sebagian besar responden menyatakan Sangat Setuju terhadap pernyataan nomor 5 .

3) Tampilan (Format) SILADDU

Untuk mengetahui bagaimana tanggapan responden tentang Tampilan (Format) SILADDU, penulis menggunakan analisis deskriptif, dengan cara menyebarkan kuisioner sebanyak 20 lembar sesuai jumlah responden, Adapun penjelasannya sebagai berikut:
TABEL 12 TANGGAPAN RESPONDEN PERNYATAAN 6

\begin{tabular}{|c|c|c|c|c|}
\hline Skala Pengkuran & Nilai & Frekuensi & Nilai Total & $\%$ \\
\hline Sangat Setuju & 5 & 0 & 0 & 0 \\
\hline Setuju & 4 & 15 & 60 & 75 \\
\hline Netral & 3 & 5 & 15 & 25 \\
\hline Tidak Setuju & 2 & 0 & 0 & 0 \\
\hline Sangat Tidak Setuju & 1 & 0 & 0 & 0 \\
\hline Jumlah & & 20 & 75 & 100 \\
\hline
\end{tabular}

TABEL 13 FORMAT 1 FREKUENSI OLEH SPSS NO. 6

\begin{tabular}{|c|c|c|c|c|}
\hline & Frequency & Percent & $\begin{array}{r}\text { Valid } \\
\text { Percent }\end{array}$ & $\begin{array}{c}\text { Cumulat } \\
\text { ive } \\
\text { Percen } \\
t\end{array}$ \\
\hline Valid $\quad \mathrm{N}$ & 5 & 25.0 & 25.0 & 25.0 \\
\hline $\mathrm{s}$ & 15 & 75.0 & 75.0 & 100.0 \\
\hline Total & 20 & 100.0 & 100.0 & \\
\hline
\end{tabular}

Berdasarkan tabel 13 diatas, bahwa responden yang memberikan tanggapan Sangat Setuju sebanyak $0 \%$. Sedangkan Setuju dengan nilai total sebesar 15 atau $75 \%$, Netral dengan nilai total sebesar 5 atau $25 \%$, Tidak Setuju dengan nilai total 0 dan begitupun dengan responden yang menyatakan Sangat Tidak Setuju. Dengan demikian dapat disimpulkan bahwa sebagian besar responden menyatakan Setuju terhadap pernyataan nomor 6 .

\section{TABEL 14 TABEL TANGGAPAN RESPONDEN PERNYATAAN 7}

\begin{tabular}{|c|c|c|c|c|}
\hline Skala Pengkuran & Nilaj & Frekuensi & Nilai Total & $\%$ \\
\hline Sangat Setuju & 5 & 0 & 0 & 0 \\
\hline Setuju & 4 & 17 & 68 & 85 \\
\hline Netral & 3 & 3 & 9 & 15 \\
\hline Tidak Setuju & 2 & 0 & 0 & 0 \\
\hline Sangat Tidak Setuju & 1 & 0 & 0 & 0 \\
\hline Jumlah & & 0 & 75 & 100 \\
\hline
\end{tabular}


TABEL 15 FORMAT 2 FREKUENSI OLEH SPSS NO. 7

\begin{tabular}{|r|r|r|r|r|}
\hline & Frequency & Percent & $\begin{array}{r}\text { Valid } \\
\text { Percent }\end{array}$ & $\begin{array}{c}\text { Cumulat } \\
\text { ive } \\
\text { Perce } \\
\text { nt }\end{array}$ \\
\hline Valid N & 3 & 15.0 & 15.0 & 15.0 \\
Total & 17 & 85.0 & 85.0 & 100.0 \\
Th & 20 & 100.0 & 100.0 & \\
\hline
\end{tabular}

Berdasarkan tabel 15 diatas, bahwa responden yang memberikan tanggapan Sangat Setuju sebanyak 0\%. Sedangkan Setuju dengan nilai total sebesar 17 atau $85 \%$, Netral dengan nilai total sebesar 3 atau 15\%, Tidak Setuju dengan nilai total 0 dan begitupun dengan responden yang menyatakan Sangat Tidak Setuju. Dengan demikian dapat disimpulkan bahwa sebagian besar responden menyatakan Setuju terhadap pernyataan nomor 7 .

4) Kemudahan (Ease of Use) SILADDU

Untuk mengetahui bagaimana tanggapan responden tentang Kemudahan (Ease of Use) SILADDU, penulis menggunakan analisis deskriptif, dengan cara menyebarkan kuisioner sebanyak 20 lembar sesuai jumlah responden, Adapun penjelasannya sebagai berikut:

TABEL 16 TABEL TANGGAPAN RESPONDEN PERNYATAAN 8

\begin{tabular}{|c|c|c|c|c|}
\hline Skala Pengkuran & Nilai & Frekuensi & Nilai Tota & $\%$ \\
\hline Sangat Setuju & 5 & 0 & 0 & 0 \\
\hline Setuju & 4 & 19 & 76 & 95 \\
\hline Netral & 3 & 1 & 3 & 5 \\
\hline Tidak Setuju & 2 & 0 & 0 & 0 \\
\hline Sangat Tidak Setuju & 1 & 0 & 0 & 0 \\
\hline Jumlah & & 20 & 79 & 100 \\
\hline
\end{tabular}

TABEL 17 TABEL EASE OF USE 1 FREKUENSI OLEH SPSS NO. 8

\begin{tabular}{|cc|c|c|c|c|}
\hline & & Frequency & Percen & $\begin{array}{r}\text { Valid } \\
\text { Percent }\end{array}$ & $\begin{array}{c}\text { Cumulat } \\
\text { ive } \\
\text { Percen } \\
\mathrm{t}\end{array}$ \\
\hline Valid & $\mathrm{N}$ & 1 & 5.0 & 5.0 & 5.0 \\
& $\mathrm{~S}$ & 19 & 95.0 & 95.0 & 100.0 \\
& Total & 20 & 100.0 & 100.0 & \\
\hline
\end{tabular}

Berdasarkan tabel 17 diatas, bahwa responden yang memberikan tanggapan Sangat Setuju sebanyak 0\%. Sedangkan Setuju dengan nilai total sebesar 19 atau 95\%, Netral dengan nilai total sebesar 1 atau 5\%, Tidak Setuju dengan nilai total 0 dan begitupun dengan responden yang menyatakan Sangat Tidak Setuju. Dengan demikian dapat disimpulkan bahwa sebagian besar responden menyatakan Setuju terhadap pernyataan nomor 8 .

\section{TABEL 18 TABEL TANGGAPAN RESPONDEN PERNYATAAN 9}

\begin{tabular}{|c|c|c|c|c|}
\hline Skala Pengkuran & Nilai & Frekuensi & Nilai Total & $\%$ \\
\hline Sangat Setuju & 5 & 0 & 0 & 0 \\
\hline Setuju & 4 & 16 & 64 & 80 \\
\hline Netral & 3 & 4 & 12 & 20 \\
\hline Tidak Setuju & 2 & 0 & 0 & 0 \\
\hline $\begin{array}{c}\text { Sangat Tidak } \\
\text { Setuju }\end{array}$ & 1 & 0 & 0 & 0 \\
\hline Jumlah & & 20 & 76 & 100 \\
\hline
\end{tabular}

TABEL 2.19 TABEL EASE OF USE 2 FREKUENSI OLEH SPSS NO. 9

\begin{tabular}{|c|c|c|c|c|c|}
\hline & & Frequency & Percent & $\begin{array}{l}\text { Valid } \\
\text { Percent }\end{array}$ & $\begin{array}{c}\text { Cumulat ive } \\
\text { Percent }\end{array}$ \\
\hline \multirow[t]{3}{*}{ Valid } & & 4 & 20.0 & 20.0 & 20.0 \\
\hline & $\mathrm{s}$ & 16 & 80.0 & 80.0 & 100.0 \\
\hline & Total & 20 & 100.0 & 100.0 & \\
\hline
\end{tabular}

Berdasarkan tabel 19 diatas, bahwa responden yang memberikan tanggapan Sangat Setuju sebanyak 0\%. Sedangkan Setuju dengan nilai total sebesar 16 atau $80 \%$, Netral dengan nilai total sebesar 4 atau 20\%, Tidak Setuju dengan nilai total 0 dan begitupun dengan responden yang menyatakan Sangat Tidak Setuju. Dengan demikian dapat disimpulkan bahwa sebagian besar responden menyatakan Setuju terhadap pernyataan nomor 9 .

5) Ketepatan (Timeleines)

Untuk mengetahui bagaimana tanggapan 
responden tentang Kemudahan (Ease of Use) SILADDU, penulis menggunakan analisis deskriptif, dengan cara menyebarkan kuisioner sebanyak 20 lembar sesuai jumlah responden, Adapun penjelasannya sebagai berikut:

TABLE 20 TABEL TANGGAPAN RESPONDEN PERNYATAAN 10

\begin{tabular}{|c|c|c|c|c|}
\hline Skala Pengkuran & Nilai & Frekuensi & Nilai Total & $\%$ \\
\hline Sangat Setuju & 5 & 0 & 0 & 0 \\
\hline Setuju & 4 & 17 & 68 & 85 \\
\hline Netral & 3 & 3 & 9 & 15 \\
\hline Tidak Setuju & 2 & 0 & 0 & 0 \\
\hline $\begin{array}{c}\text { Sangat Tidak } \\
\text { Setuju }\end{array}$ & 1 & 0 & 0 & 0 \\
\hline Jumlah & & 20 & 77 & 100 \\
\hline
\end{tabular}

TABEL 21 TABEL TIMELINESS 1

FREKUENSI OLEH SPSS NO.10

\begin{tabular}{|c|c|c|c|c|}
\hline & Frequency & Percent & $\begin{array}{r}\text { Valid } \\
\text { Percent }\end{array}$ & $\begin{array}{c}\text { Cumulat } \\
\text { ive } \\
\text { Perce } \\
\text { nt }\end{array}$ \\
\hline Valid $\quad N$ & 3 & 15.0 & 15.0 & 15.0 \\
\hline $\mathrm{S}$ & 17 & 85.0 & 85.0 & 100.0 \\
\hline Total & 20 & 100.0 & 100.0 & \\
\hline
\end{tabular}

Berdasarkan tabel 20 diatas, bahwa responden yang memberikan tanggapan Sangat Setuju sebanyak 0\%. Sedangkan Setuju dengan nilai total sebesar 17 atau $85 \%$, Netral dengan nilai total sebesar 3 atau $15 \%$, Tidak Setuju dengan nilai total 0 dan begitupun dengan responden yang menyatakan Sangat Tidak Setuju. Dengan demikian dapat disimpulkan bahwa sebagian besar responden menyatakan Setuju terhadap pernyataan nomor 10 .

TABEL 22 TABEL TANGGAPAN RESPONDEN PERNYATAAN 11

\begin{tabular}{|c|c|c|c|c|}
\hline Skala Pengkuran & Nilai & Frekuensi & Nilai Total & $\%$ \\
\hline Sangat Setuju & 5 & 0 & 0 & 0 \\
\hline Setuju & 4 & 19 & 76 & 95 \\
\hline Netral & 3 & 1 & 3 & 5 \\
\hline Tidak Setuju & 2 & 0 & 0 & 0 \\
\hline $\begin{array}{c}\text { Sangat Tidak } \\
\text { Setuju }\end{array}$ & 1 & 0 & 0 & 0 \\
\hline Jumlah & & 20 & 79 & 100 \\
\hline
\end{tabular}

TABEL 23 TABEL TIMELINESS 2 FREKUENSI OLEH SPSS

\begin{tabular}{|c|c|c|c|c|c|}
\hline & & Frequency & Percent & $\begin{array}{r}\text { Valid } \\
\text { Percent }\end{array}$ & $\begin{array}{l}\text { Cumulat } \\
\text { ive } \\
\text { Percent }\end{array}$ \\
\hline \multirow[t]{3}{*}{ Valid } & $\mathrm{N}$ & 1 & 5.0 & 5.0 & 5.0 \\
\hline & $\mathrm{s}$ & 19 & 95.0 & 95.0 & 100.0 \\
\hline & Total & $2 d$ & 100.0 & 100.0 & \\
\hline
\end{tabular}

Berdasarkan tabel 22 diatas, bahwa responden yang memberikan tanggapan Sangat Setuju sebanyak 0\%. Sedangkan Setuju dengan nilai total sebesar 19 atau 95\%, Netral dengan nilai total sebesar

1 atau 5\%, Tidak Setuju dengan nilai total 0 dan begitupun dengan responden yang menyatakan Sangat Tidak Setuju. Dengan demikian dapat disimpulkan bahwa sebagian besar responden menyatakan Setuju terhadap pernyataan nomor 11 .

C. Uji Kualitas Data

1) Uji Validitas

Uji validitas digunakan untuk mengukur sah atau valid tidaknya suatu kuesioner. Suatu kuesioner dikatakan valid jika pertanyaan pada kuesioner mampu untuk mengungkapkan sesuatu yang akan diukur oleh kuesioner tersebut. Menurut Ghozali (2006) untuk mengukur validitas dapat dilakukan dengan melakukan korelasi antar skor butir pertanyaan dengan total skor konstruk atau variabel

Uji signifikansi dilakukan dengan membandingkan nilai $r$ hitung dengan $r$ tabel untuk degree of freedom $(\mathrm{df})=\mathrm{n}$

-2 , dalam hal ini $n$ adalah jumlah sampel. Pada penelitian ini jumlah sampel $(n)=93$ dan 
besarnya df dapat dihitung $93-2=91$, dengan $\mathrm{df}=91$ dan alpha $=0,05$, didapat $\mathrm{r}$ tabel $=$ 0,204 . Untuk menguji apakah masing-masing indikator valid atau tidak dapat dilihat pada tampilan output Cronbach Alpha pada kolom Correlated Item - Total Correlation baik pada konstruk kepuasan pengguna SILADDU, kinerja individual dan kemudahan penggunaan SILADDU. Kemudian nilai Correlated Item Total Correlation dibandingkan dengan hasil perhitungan $r$ tabel $=0,204$, jika $r$ hitung $>r$ tabel dan bernilai positif maka butir atau pertanyaan tersebut dinyatakan valid.Berikut adalah hasil uji validitas data seperti yang ditunjukkan pada tabel 2.23

\section{TABEL 24 HASIL UJI VALIDITAS}

\begin{tabular}{|c|c|c|c|c|}
\hline No & $\begin{array}{c}\text { Scale Mean if } \\
\text { Item Deleted }\end{array}$ & $\begin{array}{c}\text { Scale } \\
\text { Variance } \\
\text { if Item } \\
\text { Deleted }\end{array}$ & $\begin{array}{c}\text { Corrected } \\
\text { Item- } \\
\text { Total } \\
\text { Correlation }\end{array}$ & $\begin{array}{c}\text { Cronbach's } \\
\text { Alpha if } \\
\text { Item } \\
\text { Deleted }\end{array}$ \\
\hline 1 & 38.9000 & 4.726 & .625 & .771 \\
2 & 38.8000 & 5.221 & .494 & .787 \\
3 & 39.0000 & 5.158 & .296 & .811 \\
4 & 38.8000 & 5.221 & .494 & .787 \\
5 & 38.4500 & 4.787 & .383 & .806 \\
6 & 38.9500 & 4.471 & .714 & .759 \\
7 & 38.8500 & 5.503 & .217 & .812 \\
8 & 38.7500 & 5.776 & .171 & .810 \\
9 & 38.9000 & 4.726 & .625 & .771 \\
10 & 38.8500 & 4.661 & .769 & .758 \\
11 & 38.7500 & 5.461 & .478 & .793 \\
\hline
\end{tabular}

Dari tabel 24 dapat dilihat bahwa nilai $r$ hitung Corrected Item-Total Correlation untuk indikator konstruk kepuasan pengguna SILADDU, kinerja

individual dan kemudahan penggunaan SILADDU> dari $r$ tabel 0,204.Sehingga dapat diambil kesimpulan bahwa semua indikator konstruk kepuasan pengguna SILADDU, kinerja individual dan kemudahan penggunaan SILADDU adalah valid.

\section{2) Uji Reliabilitas}

Kualitas data yang dihasilkan dari penggunaan instrumen penelitian dapat dievaluasi melalui uji reliabilitas dan validitas.Uji tersebut masingmasing untuk mengetahui konsistensi dan akurasi data yang dikumpulkan dari penggunaan
instrumen.Untuk mengukur reliabilitas dengan uji statistik Cronbach Alpha. Suatu konstruk atau variabel dikatakan reliabel jika memberikan nilai Cronbach alpha > 0,60 (Nunnaly,1967) (dalam Ghozali 2006). Berikut adalah hasil uji reliabilitas yang ditunjukkan pada tabel 2.24

TABEL 25 RELIABILITY STATISTICS

\begin{tabular}{|c|c|}
\hline $\begin{array}{c}\text { Cronbach's } \\
\text { Alpha }\end{array}$ & $\begin{array}{c}\text { N of } \\
\text { Items }\end{array}$ \\
\hline .804 & 11 \\
\hline
\end{tabular}

Dari hasil output reliability, variabel kepuasan pengguna SILADDU menunjukkan reliabel dengan cronbach alpha 0,664 yang berarti 0,664 $>$ 0,60. Hasil tersebut menunjukkan bahwa semua pertanyaan mengenai kepuasan pengguna SILADDU adalah reliabel.

3) Pembahasan

Pembahasan berikut bertujuan menjelaskan tentang hasil yang diperoleh dari hasil penelitian yang telah dilakukan.

Dari hasil penelitian yang dilakukan peneliti dengan data-data primer yang telah dikumpulkan dan diolah dengan SPSS menunjukan bahwa tingkat kepuasan pengguna terhadap Aplikasi SILADDU yaitu dinyatakan berhasil. Hasil prosentasi yang dihasilkan dari setiap pernyataan yang tertera dalam kuisioner menunjukan hasil yang memuaskan . dari sebelas pernyataan yang terbagi dalam lima unsur yaitu Isi (Content), Keakuratan (Accuracy), Tampilan (Format), Kemudahan (Easy of Use) dan Ketepatan (Timeliness) ratarata yang menjawab Setuju merupakan jawaban yang paling banyak dipilih oleh responden. Dan hasil itu menunjukan bahwa aplikasi SILADDU terbilang berhasil dan sesuai harapan pengguna.

\section{KESIMPULAN}

\section{Kesimpulan}

Dari hasil statistik yang terdapat pada laporan, penulis menyumpulkan beberapa kesimpulan:

1. Untuk hasil dari komponen Isi(Content) yang terdapat tiga pernyataan didalamnya responden memilih Setuju dengan hasil lebih dari $80 \%$. 
2. Untuk hasil dari komponen Keakuratan(Accuracy) yang terdapat dua pernyataan didalamnya diperoleh juga $80 \%$ untuk pilihan Setuju.

3. Kompnen Tampilan(Format) juga menghasilkan rata-rata $80 \%$ lebih untuk pilihan Setuju.

4. Hasil dari pilihan responden untuk komponen Kemudahan(Ease of Use) lagilagi memperoleh rata-rata $80 \%$ dengan pilihan Setuju.

5. Komponen Ketepatan(Timeliness) juga mendapat angka rata-rata $80 \%$ untuk pilihsn jawaban Setuju.

\section{Saran}

Saran yang dapat penulis berikan terhadap peneliti berikutnya yaitu:

1. Diharapkan peneliti berikutnya agar menambah sampel supaya keakuratan data lebih baik lagi.

2. Penulis mengharapkan agar peneliti berikutnya juga menggunakan lebih dari satu variabel dalam melakukan penelitian ini.

3. Memperbanyak model untuk mengukur kepuasan pengguna.

4. Penulis harapkan untuk peneliti berikutnya juga memasukan metode wawancara yang dapat dimasukan dalam kesimpulan untuk hasil penelitiannya.

\section{REFERENSI}

Adianto, D., \& Sujadi, H. (2016). Aplikasi Sistem Pendukung Keputusan Pemilihan Jurusan Siswa-Siswi SMA (Mipa/Ips/Bahasa) Menggunakan Metode Ahp. J-Ensitec, 3(01).

Tjiptono, Fandy., Gregorius Chandra. (2011). Service, Quality, \& Satisfaction, Edisi 3 Yogyakarta: Andi

Kotler, P. (2003). Marketing management: Analysis, planning, implementation and control, 11th ed., New Jersey: Prentice Hall.

Gupta M.P, Kanungo S, Kumar R and Sahu G.P,2007. "A Study of Information Technology Efectiveness in Select Government Organizationsin India". Journal for Decision Makers. Vol 32. No.2.

Sebayang, Firmanta. 2009. Ketersediaan Sistem Informasi Terintegrasi Terhadap Kepuasan Pengguna. Jurnal Keuangan dan Perbankan,
Vol.13, No.2 Mei 2009, hal.325-336.

Supriyatna, Dicky, dan Jin, Fung, Tjhai., (2006). Analisis Pengaruh Kepuasan Pengguna Public Computer Terhadap Efisiensi dan Efektivitas Mahasiswa Trisakti School of Management. Jurnal Bisnis dan Akuntansi. Vol.8, No.2, Agustus 2006, 111-134.

Mardiana, A. (2016). Tingkat Kepuasan Mahasiswa Terhadap Kinerja Sistem Informasi Akademik dan Keuangan (Studi Kasus: Universitas Majalengka). INFOTECH journal, 1(2). 